\title{
Degradation of Solid Dielectrics due to Internal Partial Discharge: Some thoughts on progress made and where to go now
}

\author{
Peter H.F. Morshuis \\ High Voltage Technology \& Management \\ Delft University of Technology \\ Mekelweg 4, 2628 CD Delft \\ The Netherlands
}

\begin{abstract}
The amount of literature on partial discharge (PD) and partial discharge induced degradation is vast. In the past 10 - 20 years significant progress has been made on research within partial discharge induced aging of dielectrics. Researchers now agree on the main mechanisms pertaining to this topic. With the advent of a new generation of dielectrics of which many properties now can be affected by the introduction of small amounts of nano-sized particles it seems to be a good moment to review the progress on the understanding of PD induced aging. Focusing on internal partial discharge in solid polymeric insulation this paper tries to identify achievements and at the same time challenges still to be solved.
\end{abstract}

Index Terms — Partial discharges, internal PD, aging, dielectric breakdown.

\section{INTRODUCTION}

PARTIAL discharges and the way they affect insulation quality has for decades been a rewarding subject for many researchers. In the past 10 years the number of papers per year addressing this topic has decreased and much more focus was put upon topics like automatic analysis and classification procedures for PD. The advent of powerful hardware has led to an extensive exploration and development of pattern recognition techniques that were earlier introduced in other fields. So, are the PD induced degradation mechanisms sufficiently well understood? After all the efforts that were made in the last century, we might expect this to be the case. Therefore, it is the aim of this paper to summarize what has been achieved in this field, with emphasis on the past 20 years. Some questions left unanswered will be identified and the importance of answering these questions will be discussed. As will become clear, the author is of the opinion that, especially by developments like the introduction of new generations of dielectrics, the field of PD induced degradation has again gained importance.

Topics like PD diagnostics, feature extraction, and signal conditioning are not dealt with in this paper although they might appear sometimes in the sideline. The reader is referred to $[1,2]$ and to another paper in this Digest which addresses

Manuscript received on 6 February 2005, in final form 4 July 2005 these topics [3].

Although this paper focuses on the work on PD degradation in the last two decades, it needs to be mentioned that the work done in the 60's by for instance Devins [4], Mason [5] and Lacoste [6] set the stage for much of the work that followed. See also [7] for the early history of partial discharge.

It is not the purpose of this paper to present a comprehensive review. The field of PD aging is vast and therefore the discussion in this paper is restricted to PD induced aging processes due to internal PD in cavities in solid dielectrics. The paper is organized such that the process of PD induced degradation is discussed in a logic order. First, the conditions are described for PD inception in different solid insulation systems. The interaction of PD with the insulation is described in the next section. Parameters that affect this interaction, like voltage frequency, temperature and space charge are singled out and examined. At the end of each section, the questions still left to answer will be mentioned.

\section{INTERACTION BETWEEN PARTIAL DISCHARGE AND INSULATION}

PD induced degradation of the dielectric is roughly due to two processes; chemical degradation and physical attack by bombardment of particles (nitrogen ions). The interaction 
between PD in a cavity and the surrounding dielectric is complex and many effects have been identified and studied. Part of the complexity stems from the fact that the dielectric is changed (aged) due to the PD activity but at the same time the PD mechanism is affected by the aging dielectric [8,9].

The scenario depicted here considers the situation of a flat cavity or a gap between electrodes covered by a dielectric in which hydrogen, carbon and oxygen are present, either in the gas or in the dielectric. The aging process is now more or less generally accepted to proceed along the following lines, see Figure 1.

1. The conductivity of the surface of the cavity increases due to the reaction processes of humidity and the dissociation products of air as caused by the pd. Indeed, many authors have detected an increase of the surface conductivity not long after the pd process was initiated [for PE: [10]; for epoxy: [11]. When the cavity surface is observed more closely, often a liquid layer or droplets are found.

2. In the following stage the surface roughness is seen to increase due to charge carrier bombardment and deposition of pd by-products.

3. Further pd activity leads to the formation of localized solid by-products, i.e. crystals which have been positively identified as hydrated oxalic acid [12].

4. The field enhancement at crystal tips leads to a further intensification and localization of the PD process and often pit formation is now observed. As a consequence tree growth is initiated.

5. Eventually, the tree growth may lead to breakdown.

When fillers are present in the dielectric, the insulation between filler particles usually is most severely degraded.

$\begin{array}{lll}\begin{array}{l}\text { Change of } \\ \text { surface }\end{array} & \begin{array}{l}\text { Concentration } \\ \text { of the discharge }\end{array} & \begin{array}{l}\text { Change in } \\ \text { the insulation }\end{array}\end{array}$

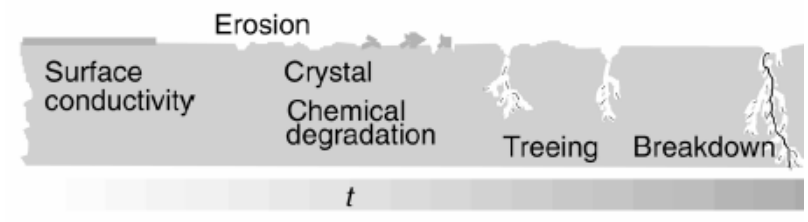

Figure 1. Stages of PD-induced damage at the insulator surface, after Temmen [9].

In sections $2.1-2.3$ the progression of PD induced degradation will be explored in some detail. The intricate interaction between PD mechanism and aging dielectric is dealt with in section 2.4 .

\subsection{CHEMICAL REACTION BETWEEN THE GAS AND THE SOLID DIELECTRIC}

Initially, chemical reactions take place in which the humidity and dissociation products of the air play a major role. The chemical reactions that accompany the interaction between PD and solid dielectric have been extensively studied. Complicated as these processes are, the evolution of the chemical by-products from the start of the PD induced aging process is now well established. The chemical reactions result in both gaseous, liquid and solid by-products. Most studies were directed towards either polyethylene (or a derivative thereof) or epoxy. References are given in the following sections.

\subsubsection{GASEOUS BY-PRODUCTS}

Garcia [13] investigated by gas chromatography techniques the gases produced in an aging cell in which LDPE and XLPE were exposed to PD activity. A large amount of carbon monoxide and carbon dioxide was found and a very small amount of hydrogen. In another experiment the gaseous composition of electrical trees in which PD were developing was analyzed by a spectroscopic method. The principal gases in this experiment were again the carbon oxides and hydrogen.

These results were confirmed by Wolter et al. [14,15] who studied the gaseous by-products of low density polyethylene exposed to corona discharges. The main degradation products were found to be hydrogen, carbon monoxide, methane and carbon dioxide. The formation of hydrogen was shown to be the direct result of the interaction between the polymer and the radiative energy of the discharge. The oxidation of fragments of polymer chains were believed to lead to the formation of the carbon oxides.

\subsubsection{LIQUID BY-PRODUCTS}

The deposition of liquid by-products has been reported by many authors, mainly for polyethylene [16-20] and epoxy [2125]. Gamez-Garcia et al. [26] showed that droplets were formed on the surface of XLPE only when an atmosphere containing water and carbon monoxide was present. The droplets were found to be a mixture of simple organic compounds, like formic, acetic and carboxylic acids. Morshuis showed that if one of the constituents $\mathrm{H}, \mathrm{C}$ or $\mathrm{O}$ was absent no droplets appeared [16].

Hudon [24] examined the liquid droplets, an example of which is shown in Figure 2, that appeared on an epoxy surface after PD activity. The nature of these droplets was found to be acidic and with ion chromatography glyoxylate, glycolate and formate were detected.

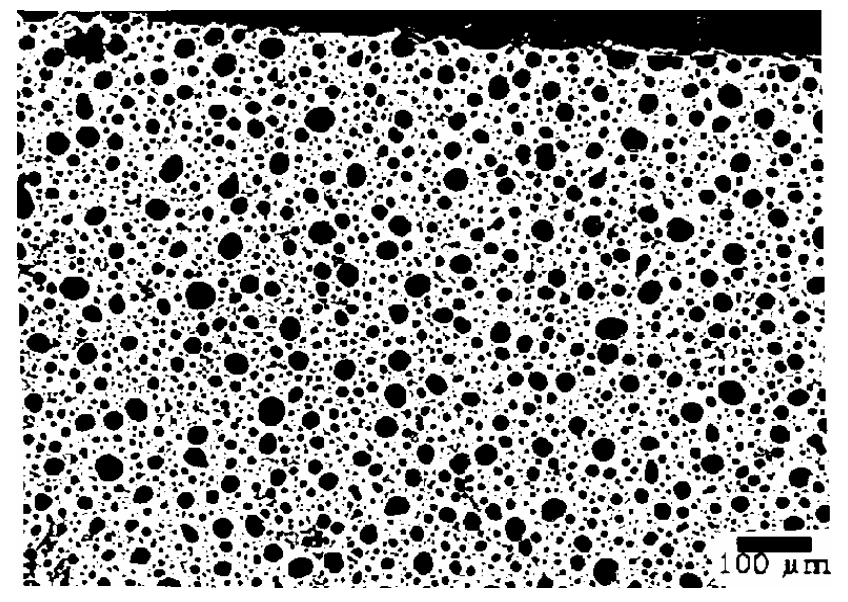

Figure 2. Drops covering an epoxy surface after a short duration of PD exposure [11]. 
One of the major effects of the formation of liquid byproducts is the strong increase of the surface conductivity of the cavity walls. This is caused by the fact that degradation products are dissolved in water and create an acid electrolytic layer. In Figure 3 it is shown that the surface conductivity increases by 6 to 7 orders of magnitude.

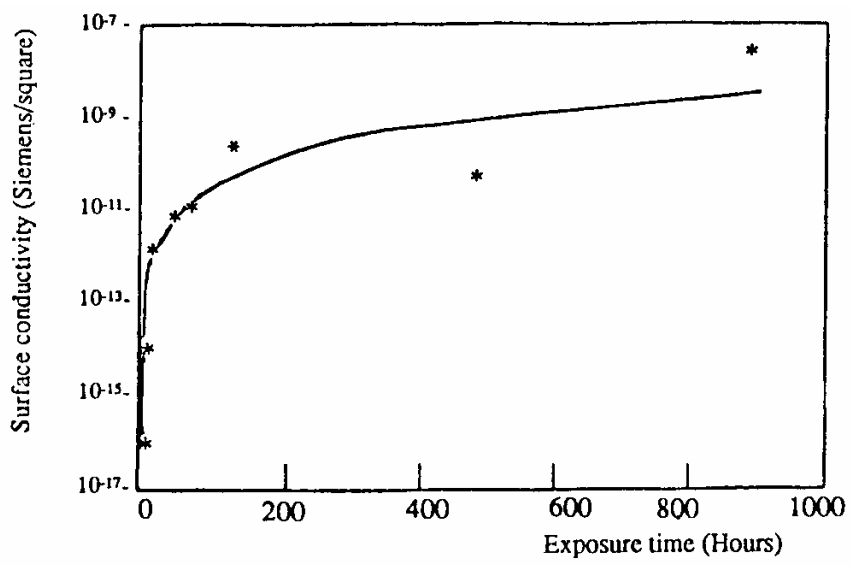

Figure 3. Conductivity of epoxy surface as a function of discharge exposure duration [21].

\subsubsection{SOLID BY-PRODUCTS}

After some hundreds of hours of PD activity local deposits of solid by-products are found. These by-products appear in the form of crystals which have been positively identified as hydrated oxalic acid $\left(\mathrm{C}_{2} \mathrm{H}_{2} \mathrm{O}_{4} \cdot 2 \mathrm{H}_{2} \mathrm{O}\right)$ by Hudon et al [12] for epoxy. In Figure 4 an example is shown of crystals observed in case of polyethylene.

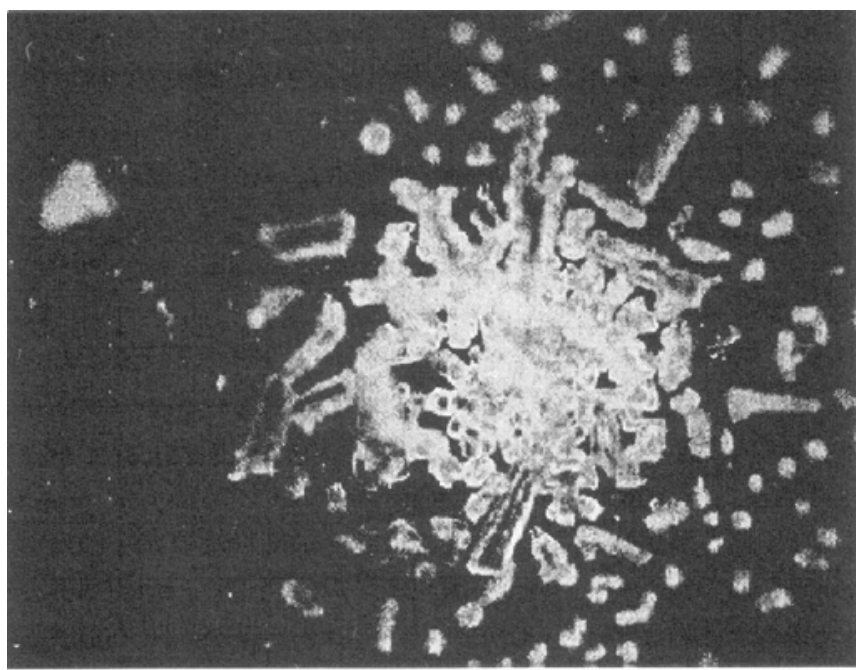

Figure 4. Cluster of crystals after $100 \mathrm{~h}$ of pd activity in a cavity in polyethylene [29] .

Crystals were only found to appear in an atmosphere in which $\mathrm{H}, \mathrm{C}$ and $\mathrm{O}$ were present [14]. There is ample evidence that the droplets deposited in an earlier stage are crystallized at the point of PD impact $[16,27,28]$.

Hudon [23] studied possible material degradation below the epoxy specimen surface and found a dark yellow colored region extending some $300 \mu \mathrm{m}$ below the surface. Some fine channels were found to extend into the "undamaged" epoxy. It was not possible to determine whether the channels were electrical trees or a result of the cleaving of the specimen.

\subsection{LOCALIZATION OF PD ACTIVITY}

Initially, in a virgin cavity, PD's have no preferential point of impact if we assume that there are no asperities at the surface of the cavity and the cavity is of oblate spheroidal shape with a more or less uniform field inside. This is supported by video recordings that were made of the $\mathrm{PD}$ process in the cavity [29]. It was observed that PD in the initial stages of aging move across the cavity surface.

When crystal-like asperities appear, local field enhancement results and it is seen that PD become localized phenomena concentrating at the tips of the crystals. In this stage the measured PD magnitude decreases sharply, but locally the PD energy density increases.

\subsection{TREE INITIATION}

An electrical tree may start to grow from a point of field enhancement (such as an asperity at the electrode-dielectric interface) or from a gaseous cavity [30]. For a tree to be initiated from a gaseous cavity, the PD activity in the cavity needs to be concentrated in a certain area. In the case of a prolate, needle shaped cavity this condition is automatically fulfilled. For a more oblate, flat cavity, crystal growth on the surface localizes the PD activity and a severe degradation of the insulation results, see Figure 5.
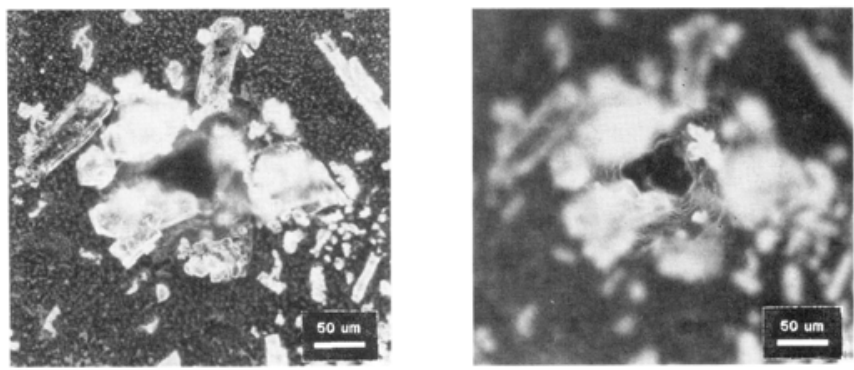

Figure 5. Severe degradation of the polyethylene surface of a cavity; in the vicinity of crystals a crater is observed. The left and right photograph were focussed on the cavity surface, resp. on the crater surface [29].

Sharp pits are now observed, enhancing the electric field into the insulation and initiating an electrical tree. For flat cavities it was confirmed by optical measurements that tree growth always starts in the direct vicinity of crystals.

Garcia Colon [31] using micro charge probes, found that at the pits a strong injection of electrons takes place. This supports the theory that from these pits a treeing process may start.

\subsection{INTERACTION BETWEEN THE AGING DIELECTRIC AND THE PD}

The conditions for discharge ignition are strongly affected by the damage to the dielectric as a result of the PD activity. Two important methods that have been used for studying this interaction are time-resolved recording of the PD pulse shape and recording of the PD phase distribution, with or without synchronous optical recording of PD light emission. 

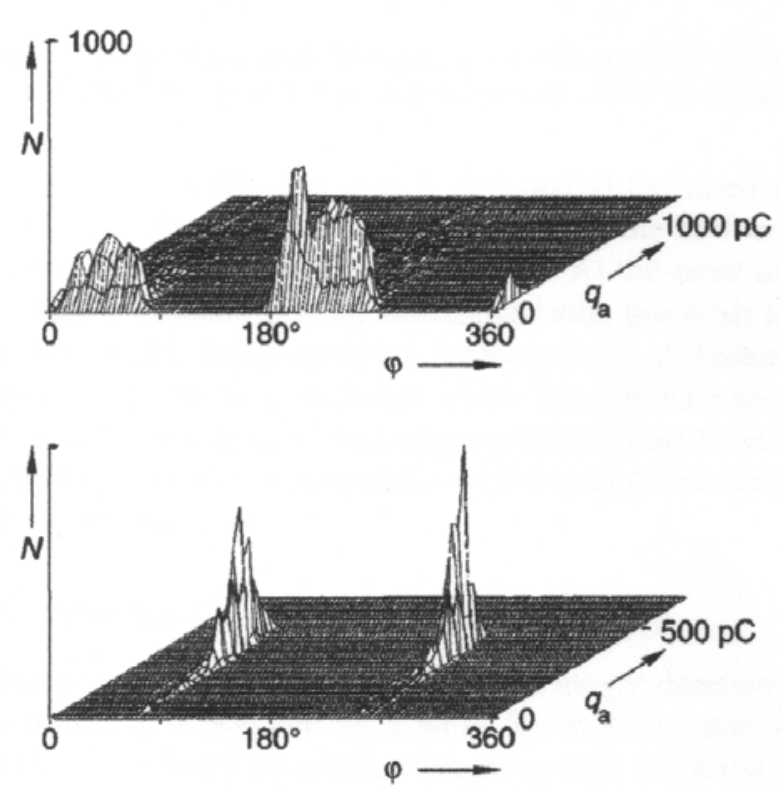

Figure 6. The influence of the surface conductivity of mica-epoxy resin on the PD phase pattern. Top: virgin sample; bottom: aged sample [9]

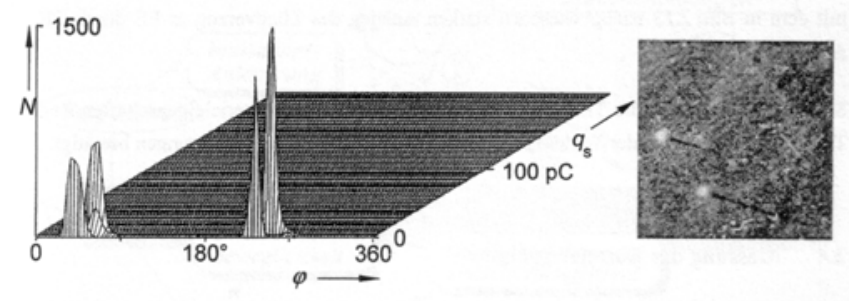

Figure 7. left: PD phase distribution of a pd-aged mica-epoxy resin surface; right: an accompanying photograph of the surface [9]

\subsubsection{PD PHASE DISTRIBUTION}

The PD inception voltage is initially determined by the superimposition of the externally applied field and the field due to surface charges deposited by earlier PD. Temmen [9] recorded the PD phase patterns during the consecutive stages of the PD induced aging process. The changes of the patterns were attributed to changes occurring at a (flat) mica-epoxy resin cavity surface.

The increased surface conductivity has a threefold effect. First, the charge deposited by earlier PD spreads out over a larger surface area and the charge induced field decreases. The electric field in the cavity thus recovers more quickly and the cavity is again discharged. Secondly, the conductive surface layer acts as a reservoir of possible initiatory electrons which are trapped in shallow traps. Thirdly, the cavity may stop discharging altogether when the high conductivity of the cavity walls prevents the build-up of a sufficiently high field inside the cavity. This may especially be observed in prolate cavities in which the cavity walls form an important part of the total cavity surface.

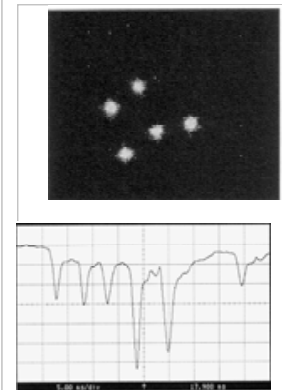

(a)
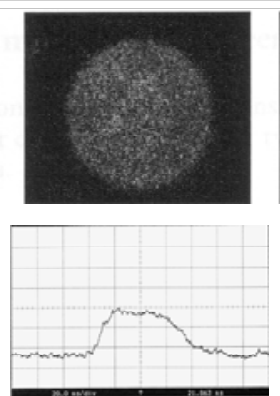

(b)
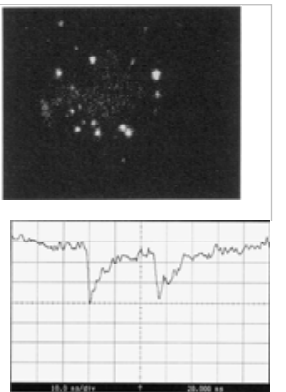

(c)
Figure 8. Optical (top) and electrical (bottom) recordings of PD activity. (a) Parallel, streamer-like PD events in a virgin, polyethylene cavity; (b) Single, diffuse Townsend-like PD in a slightly aged cavity;

(c) Minute discharge pulses (pitting) in a significantly aged cavity [29].

Therefore, the statistical time lag for obtaining an initiatory electron decreases and PD are seen to ignite as soon as the externally applied field crosses the minimal inception field. This results in a narrowing of the PD phase distribution. Last, the increased surface conductivity prevents the occurrence of parallel PD sites. In Figure 6 [9] plots are shown that illustrate this behavior, i.e. the PD pattern is very narrow. The change from a situation with parallel PD sites to a situation in which only a single PD is observed also becomes evident from optical studies of the PD process. This is discussed in the next section.

In a later stage of the aging process crystals appear and PD ignite at the crystal tips. The local PD ignition voltage is decreased by the field enhancement at the crystal tip. The PD magnitude is very small because of the very limited size of the area involved. In Figure 7 a photograph is shown of the cavity surface on which two crystals have grown.

The ignition of PD at the two sites can be clearly identified in the PD phase distribution.

\subsubsection{PD MECHANISM, PULSE SHAPE AND OPTICAL IMAGE}

Several authors have studied the PD pulse shape as a means to obtain information on the PD mechanism. In some cases $[29,32]$ a simultaneous optical and electrical recording of the PD process was used to obtain additional information on the physics of the PD process. Depending on the shape of the cavity, i.e. spherical or flat, the pulse shape of the PD was found to change with progressing aging of the dielectric.

For flat cavities in polyethylene the author [29] found a characteristic pulse shape for every aging stage. Initially, narrow pulses of large magnitude (streamer-like) appear in the virgin cavity. These PD discharge only part of the cavity surface and often parallel PD events are seen, both in the electrical and optical recordings, see Figure 8a.

When a conductive layer appears at the cavity surface, the PD pulse shape becomes wide and of low amplitude (Townsend-like), see Figure 8b. Devins [4] was the first to show that the PD pulse shape is determined by the degree at which the PD ignition voltage exceeds the minimum breakdown voltage. For small values of this overvoltage a 
Townsend-like PD mechanism was observed while for large values streamer-like PD were observed. It was shown $[29,4]$ that the changing PD mechanism can indeed be explained by a changing overvoltage value. The author [29] claimed therefore that the changes of PD mechanism during the first stages of the aging process were inflicted by a decreasing overvoltage due to a reduced time lag. The reduced time lag was attributed to the increasing number of shallow trapping sites at the cavity surface.

In the aging stage when crystals appear, the PD pulse shape changes to small amplitude and intermediate pulse width, see Figure $8 \mathrm{c}$. These PD were named pitting PD due to the fact that in their presence pits appeared at the cavity surface.

Hudon et al [21,24] studied the PD behavior in an $0.5 \mathrm{~mm}$ air gap between epoxy covered electrodes in an unvented test cell. Initially, they detected large amplitude discharges that they named spark-type. These discharges seem to be comparable with streamer-like PD mentioned earlier. After some hundreds of hours also another type of pulse was detected. This type, Townsend-like, looks similar to the pulses detected in the flat cavity. The fact that in this case Townsendlike pulses were detected only after a long time of aging can be attributed to the size of the air gap $(0.5 \mathrm{~mm})$ which is large compared to the cavity thickness $(0.1 \mathrm{~mm})$ and favors the occurrence of the streamer-like type [29]. Up to $800 \mathrm{~h}$ very small amplitude PD were observed that were attributed to a pseudo-glow discharge mechanism. In this stage a remarkable increase in the number of crystals was observed. This pseudoglow stage probably is quite similar to the pitting mechanism mentioned by Morshuis. After some $800 \mathrm{hr}$ no PD were measured with a sensitivity of about $1 \mathrm{pC}$. The authors claimed the existence of a glow-type discharge process, given the fact that they still detected light in the air gap.

For spherical cavities in epoxy, Holbøll showed that in 1 $\mathrm{mm}$ diameter spherical cavities in epoxy a fast, streamer-like discharge and a slow, diffuse discharge occurred, see Figure 9. No clear transition was observed from the streamer-like to the diffuse mechanism, like for the flat cavities discussed earlier.

\section{THE EFFECT OF TEMPERATURE}

The temperature evidently has an effect on the aging process due to partial discharges. This effect can be regarded, but not exclusively, as due to the acceleration of chemical aging processes.

Gamez-Garcia et al [34] studied the modification of XLPE exposed to $\mathrm{PD}$ at temperatures up to $160^{\circ} \mathrm{C}$ using an air gap of $50 \mu \mathrm{m}$. They found a change in nature of the reaction products at the gap surface but more importantly, enhanced bulk and surface oxidation was observed with rising temperature. To obtain an indication of the aging of the polyethylene infrared spectroscopy was used to monitor the carbonyl band at 1715 $\mathrm{cm}^{-1}$. The carbonyl concentration was found to rise monotonically with temperature, with a sharp rise between 80 and $100{ }^{\circ} \mathrm{C}$. Figure 10 shows a plot corresponding to $12 \mathrm{~h}$ of $\mathrm{PD}$ exposure in which three different temperature regimes can be identified. This behavior seems to have a good correspondence with the thermal expansion of XLPE which is represented by the dashed curve. One of the major effects of temperature was thus concluded to be the permeation of oxidizing species into the bulk of the polyethylene.

Gjærde [35,36] studied the combined effect of PD and temperature up to $80{ }^{\circ} \mathrm{C}$ in a $0.125 \mathrm{~mm}$ air gap in epoxy. Similar to the results obtained in [34] on polyethylene, a change of the nature of the PD by-products was found as a function of temperature. Interestingly, at $80{ }^{\circ} \mathrm{C}$ (the glass
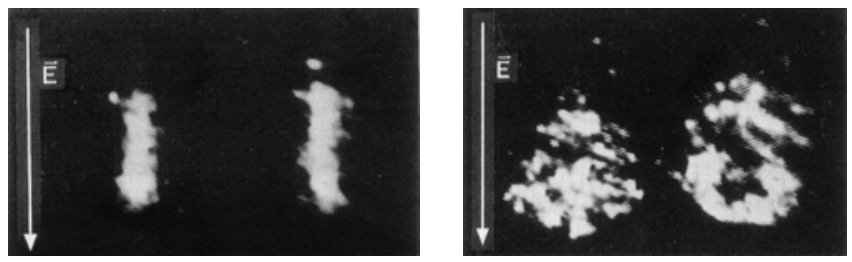

Figure 9. Optical image of left: streamer-like PD in a $3 \mathrm{~mm}$ diameter spherical cavity in epoxy; right: diffuse PD covering most of the cavity volume [33].

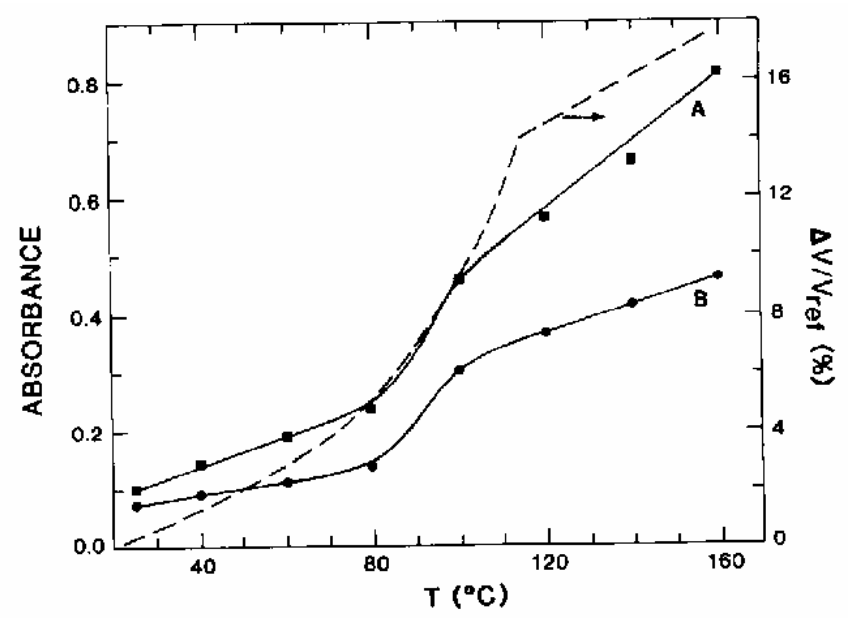

Figure 10. Carbonyl band $(1715 \mathrm{~cm}-1)$ absorbance vs. temperature (A and B) after $12 \mathrm{~h}$ of PD exposure. The dashed curve represents the volume expansion of XLPE. After [34].

transition temperature) the effect of PD was strongly reduced, resulting in a life that was longer than at 22 and $50{ }^{\circ} \mathrm{C}$. The reduced effect of $\mathrm{PD}$ at high temperature was attributed to the softening of the epoxy which would strongly reduce the erosion (physical attack) of the dielectric by PD. Part of the discharge energy would be dissipated by segmental movements of the polymer chains [37]. It was concluded [36] that not the oxidation but the physical attack on the cavity surface was the main actor in the aging process.

Di Lorenzo del Casale and Schifani [38-41] studied the effect of PD and temperature in small air gaps in epoxies using the Cigré method 2 in which an air gap is stressed with a non 
uniform field. It was found that for temperatures between 30 ${ }^{\circ} \mathrm{C}$ and $80{ }^{\circ} \mathrm{C}$ the lifetime tended to increase with temperature. This was attributed to the same effect as mentioned by Gjærde $[35,36]$, i.e. the softening of the epoxy decreases the effect of particle bombardment on the epoxy surface. In that case the glass transition temperature was however much lower $\left(80^{\circ} \mathrm{C}\right.$ in contrast to between $120{ }^{\circ} \mathrm{C}$ and $140{ }^{\circ} \mathrm{C}$ ). Further, the results are not entirely comparable, Gjærde did observe a reduction of life at $50{ }^{\circ} \mathrm{C}$ if compared to room temperature.

Di Lorenzo [41] and Schifani [42] also studied for different cavity geometries the effect of temperature on the shape of the PD phase patterns. The most evident effect was reported to be the decrease of the PD repetition rate and the increase of the PD magnitude with temperature. The decrease of the PD repetition rate was ascribed to an increase of the material "work function" with increasing temperature.

In the author's opinion there is no conclusive statement yet on the effect of temperature on PD induced aging, that is before the initiation of an electrical tree. The precise effect depends for instance on the way the PD ignition conditions are affected. A decreasing repetition rate with temperature may be explained by the increasing conductivity of the epoxy which has two effects. First, in case of the often used Cigré method 2, an increasing surface conductivity will lead to a reduced field in the air gap and consequently a reduced PD repetition rate. The increased conductivity may be the result of the higher temperature and the PD deposited by-products. Likewise, the increase of the PD magnitude with temperature could be explained by the larger area that is discharged. These are however tentative explanations and no experimental proof is available.

Regarding the effect of temperature on PD in electrical trees however, there is ample evidence that tree growth is accelerated at higher temperature and times to failure are drastically reduced $[43,44]$.

\section{QUESTIONS LEFT TO ANSWER, NEW CHALLENGES}

Not withstanding the fact that considerable progress has been made in the past two decades, there are still a few topics not explained entirely satisfactorily. On the other hand, new challenges appear on the close horizon due to the introduction of new families of dielectrics. In the following sections some of the questions and challenges will be summarized.

\subsection{PARTIAL DISCHARGE AND SPACE CHARGE}

Partial discharge and space charge are closely related; one affects the other. Charges trapped in shallow trapping sites at the boundary between dielectric and cavity serve as initiatory electrons. These charges may have been deposited by earlier PD events but they can also be the result of charge transport from the electrodes towards the cavity. The nature of these trapping sites is not quite clear; i.e. the trap depth and trap density can be estimated $[29,45]$ but to the author's knowledge estimations have never been verified by experiment. In order to understand and describe why and how the PD mechanism changes as a result of the aging cavity boundaries, it is a challenge to measure the trap distribution. A complicating factor is the fact that the properties of the cavity surface change as a result of $\mathrm{PD}$ activity.

The PD itself also acts as a source of charge injection into the dielectric. Part of the charge involved in the discharge process is trapped at the cavity surface and part of the charge migrates deeper into the dielectric. Very little literature $[31,45]$ is at present available on measurements of space charge injected by discharging cavities. It would be of great interest to study simultaneously the PD activity in a cavity and the space charge profile in the dielectric. The results of such a study might shine some light on the relation between $\mathrm{PD}$ and breakdown, especially at DC voltage.

\subsection{PARTIAL DISCHARGE AND VOLTAGE FREQUENCY}

Two developments are of importance when we consider the effect of voltage frequency on $\mathrm{PD}$ and on $\mathrm{PD}$ induced degradation. The behavior of $\mathrm{PD}$ at $\mathrm{DC}$ voltage is not considered here, more information on this topic can be found in [46].

First, we observe the introduction of a number of PD test systems on the market for onsite PD detection on cable systems $[47,48]$. These systems, although based on different principles, have one common property: they operate at voltage frequencies other than $50 / 60 \mathrm{~Hz}$. This development is of importance regarding the effect the frequency has on the measured discharge pattern, not so much regarding PD induced aging.

The second development is of much larger consequence; the introduction of power electronics systems (inverter stations) has led to insulation systems being stressed with repetitive transients of relatively high frequency [49]. It is clear that PD due to short rise time voltage surges have a strongly detrimental effect on the insulation [50]. The effect on the PD behavior of the resulting voltage distortion which can be both of unipolar and bipolar nature is not satisfactorily explained yet. An intricate interaction between injected space charge and partial discharge activity complicates the understanding of these processes and warrants dedicated research.

\subsection{PARTIAL DISCHARGE AND ITS EFFECT ON NANO-STRUCTURED DIELECTRICS}

Research on the effect of nano-structuring of dielectrics on their PD resistance has only just started [51-53]. It seems that some combinations of nano filler and host dielectric remarkably improve the $\mathrm{PD}$ resistance of the dielectric.

For instance it was found [54] that the introduction of 2-5 weight percent of nano filler in a polyamid strongly reduced the increase in surface roughness due to PD, see Figure 11. 
Other proof of the positive effect of nano structuring on PD resistance can be found in [51,52,55-58].

Although some first theories have been published on the possible mechanism responsible, many questions are still to be answered on this topic. More information on this topic can be found in a paper by Tanaka [59] which will also appear in this digest.

\subsection{INTERACTION OF PD AND MECHANICAL STRESS}

It has been know for some years now that mechanical stress has an effect on the PD induced aging process, i.e. tensile stress will accelerate tree growth and compressive stress will retard it [60]. Mechanically pre-stressing insulation can definitely have a beneficial effect on insulation resistance against PD. While many insulation constructions could well benefit from well designed pre-stressing, the effect of mechanical stress on PD is however often disregarded and deserves some more attention.

\section{CONCLUSIONS}

It has been shown that in the past $10-20$ years significant progress has been made on aging of dielectrics due to internal partial discharges. Researchers now agree on the main mechanisms pertaining to this topic. Due to a combination of chemical reactions and charge carrier bombardment the cavity surface is roughened. Deposition of discharge by products leads to field enhancement and severe local attack of the cavity surface. Finally, the formation of pits is observed and electrical tree growth is initiated. The interaction between the PD process and the aging dielectric is strong and in the course of the aging process the PD mechanism changes. This is well observed in the changing PD pulse shape and in the changing PD phase pattern.

There are a number of topics that are still not well-explored and need further development to improve the understanding of PD induced aging.

The combined effect of temperature and PD has been shown to lead to synergistic effects in some cases but there still are contradictory opinions on the nature of this interaction.

The complex relation between space charge and partial discharge has been the topic of very few studies.

Partial discharge and PD induced degradation and how they are affected by voltage of higher frequency, distorted voltages and repetitive transients ask for more attention.

The seemingly large improvement of the PD resistance of nano structured dielectrics should be further looked into. In fact, this research field has only just been entered and certainly not yet have the optimal combinations of nano material and host material been found.

The PD resistance of a dielectric in many cases can be improved significantly by mechanical pre-stressing. This topic would deserve more attention.

Summarizing, there is more than enough ground to cover in this field.

\section{REFERENCES}

[1] A. Krivda, "Automated recognition of partial discharges", IEEE Trans. Dielectr. Electr. Insul., Vol. 2, pp. 796-821, 2005.

[2] A. Cavallini, G.C. Montanari, F. Puletti and A. Contin, "A new methodology for the identification of PD in electrical apparatus: properties and applications", IEEE Trans. Dielectr. Electr. Insul., Vol. 12, pp. 203-215, 2005.

[3] G. Stone, "PD diagnostics and system reliability", IEEE Trans. Dielectr. Electr. Insul., Vol. 12, pp. , 2005 (this issue).

[4] J.C. Devins, "The physics of partial discharges in solid dielectrics", IEEE Trans. Electr. Insul., Vol. 19, pp. 475 - 495, 1984.

[5] J.H. Mason, "Discharges", IEEE Trans. Electr. Insul., Vol. 13, pp. 211$238,1978$.

[6] G. Leroy, R. Lacoste and Bui Ai, "Analytical study of degradation of solid insulating materials through ionization discharges", Proc. Intern. Conf. CERL, London, pp. 393-403, 1962.

[7] D.A. Nattrass, "Partial Discharge XVII: The early history of partial discharge research", IEEE Electr. Insul. Mag., Vol. 9, No. 4, pp. 27-31, 1993.

[8] P.H.F. Morshuis, "Time-resolved discharge measurements". International Conference on Partial Discharge Conf. Publ. No. 378, 1993.

[9] K. Temmen, "Evaluation of surface changes in flat cavities due to ageing by means of phase-angle resolved partial discharge measurement", J. Phys. D. Appl. Phys., Vol. 33, pp. 603 - 608, 2000.

[10] P.H.F. Morshuis and F.H. Kreuger, "Transition from streamer to Townsend mechanisms in dielectric voids", J. Phys. D. Appl. Phys., Vol. 23, pp. 1562 - 1568, 1990.

[11] C. Hudon, R. Bartnikas and M.R. Wertheimer, "Surface conductivity of epoxy specimens subjected to partial discharges", IEEE Intern. Sympos. Electr. Insul. Cat. No. 90 CH2727 6, pp. 153-155, 1990.

[12] C. Hudon, R. Bartnikas and M.R. Wertheimer, "Analysis of Degradation Products on Epoxy Surfaces subjected to pulse and glow type discharges", IEEE Electr. Insul. Dielectr. Phenom.(CEIDP), pp. $237-243,1991$.

[13] G. Garcia, Sur le comportement du polyethylène réticulé chimiquement soumis à l'action des décharges partielles, Ph.D. thesis Paul Sabatier University, Toulouse, 1980

[14] K.D. Wolter, J.F. Johnson and J. Tanaka, "Degradation product analysis for polymeric dielectric materials exposed to partial discharges", IEEE Trans. Electr. Insul., Vol. 13, pp. 327 - 336, 1978.

[15] K.D. Wolter, J. Tanaka and J.F. Johnson, "A Study of the Gaseous Degradation Products of Corona-exposed Polyethylene", IEEE Trans. Electr. Insul., Vol. 17, pp. 248 - 252, 1982.

[16] P. Morshuis, "Assessment of dielectric degradation by ultrawide-band PD detection", IEEE Trans. Dielectr. Electr. Insul., Vol. 2, pp. 744 760, 1995.

[17] P.H.F. Morshuis and F.H. Kreuger, "The influence of the dielectric-gas interface on the discharge mechanism in a dielectric bounded cavity", 7th Intern. Sympos. High Voltage Engineering, paper 22.07, 1991.

[18] P.H.F. Morshuis and F.H. Kreuger, "The evolution of the discharge mechanism in a dielectric bounded cavity due to surface effects", IEEE 3rd Intern. Conf. Properties and Applications of Dielectric Materials Cat. No. $91 \mathrm{CH} 2937$ 1, pp. 672-675, 1991.

[19] P. Dejean, N. Foulon, M. Goldman and H. Dejean, "Chemical Aspects of the Aging of Solid Insulating Materials Submitted to Partial Discharges", IEEE 4th Intern. Conf. Conduction and Breakdown in Solid Dielectrics, Sestri Levante, pp. 181 - 185, 1992.

[20] M. Goldman, A. Goldman and J. Gatellet, "Physical and Chemical Aspects of Partial Discharges and their Effects on Materials", IEE Proc. Sci., Measur. Techn., Vol. 142, pp. 11 - 16, 1995. 
[21] C. Hudon, R. Bartnikas and M.R. Wertheimer, "Spark-to-glow discharge transition due to increased surface conductivity on epoxy resin specimens", IEEE Trans. Electr. Insul., Vol. 28, pp. 1 - 8, 1993.

[22] C. Hudon and R. Bartnikas, "Surface and gas phase reactions arising with epoxy exposed to partial discharges". IEEE Conf. Electr. Insul. Dielectr. Phenomena (CEIDP), Cat. No. 92CH3123 7, pp. 725-734, 1992.

[23] C. Hudon, R. Bartnikas and M.R. Wertheimer, "Chemical and physical degradation effects on epoxy surfaces exposed to partial discharges", IEEE 4th Intern. Conf. Properties and Applications of Dielectric Materials Cat. No. 94CH3311 8, pp. 811-814, 1994.

[24] C. Hudon, R. Bartnikas and M.R. Wertheimer, "Effect of physicochemical degradation of epoxy resin on partial discharge behavior", IEEE Trans. Dielectr. Electr. Insul., Vol. 2, pp. 1083 - 1094, 1995.

[25] S. Christensen, Electrical Deterioration of Epoxy Plastic as a Result of Internal Discharges, Ph.D. thesis Technical University of Denmark, 1985.

[26] M. Gamez Garcia, R. Bartnikas and M.R. Wertheimer, "Synthesis reactions involving XLPE subjected to partial discharges", IEEE Trans. Electr. Insul., Vol. 22, pp. 199 - 205, 1987.

[27] N. Foulon Belkacemi, M. Goldman, A. Goldman and J. Amouroux, "Transformation of nodules into crystals on polymers submitted to corona discharges with streamers", IEE Proc. Sci., Measur. Techn., Vol. 142, pp. 477 - 481, 1995.

[28] J.T. Holbøll and M. Henriksen, "Partial discharge patterns and surface deterioration in voids in filled and unfilled epoxy", IEEE International Sympos. Electr. Insul. Cat. No. 92 CH3150 0, pp. 354-358, 1992.

[29] P.H.F. Morshuis, Partial Discharge Mechanisms, Ph.D. thesis Delft University of Technology, 1993.

[30] N. Shimizu and C. Laurent, "Electrical Tree Initiation", IEEE Trans. Dielectr. Electr. Insul., Vol. 5, pp. 651-659, 1998.

[31] V.R. Garcia-Colon Hernandez and M. Gamez-Garcia, "Evaluación de superficies de XLPE expuestas a descargas parciales mediante una microsonda electrostatica", 1st Reunión de Verano del Capítulo de Potencia, IEEE Sección México, Acapulco, pp. 1 - 6, 1988.

[32] J.T. Holbøll, J.M. Braun, N. Fujimoto and G. Stone, "Simultaneous detection of optical and electrical signals from partial discharges. Discharge phenomena in voids and epoxy", 7th International Symposium on High Voltage Engineering, paper 72.09, 1991.

[33] J.T. Holbøll, The Resistance of Composite Materials Against Electrical Discharges, Ph.D. thesis, Technical University of Denmark, 1992.

[34] M. Gamez Garcia, R. Bartnikas and M.R. Wertheimer, "Modification of XLPE exposed to partial discharges at elevated temperature", IEEE Trans. Electr. Insul., Vol. 25, pp. 688 - 692, 1990.

[35] A.C. Gjaerde, Multi factor ageing of epoxy - the combined effect of temperature and partial discharges, Ph.D. thesis Technical University Trondheim, 1994

[36] A.C. Gjaerde, "The combined effect of partial discharges and temperature on void surfaces". IEEE Conf. Electr. Insul. Dielectr. Phenomena (CEIDP), Cat. No. 97CH36046, pp. 550-553, 1997.

[37] S.N. Koikov and V.A. Fomin, "Effect of partial discharge current on the rate of breakdown of PE film", Sov. Plast., No. 3, pp. 42 - 44, 1971.

[38] M. Di Lorenzo del Casale, G. Mirelli and R. Schifani, "On PD insulation ageing under electrical and thermal multistress in CIGRE method II: a methodologic approach", Nordic Insul. Sympos., NORD IS 99, pp. 149-156, 1999.

[39] M. Di Lorenzo del Casale, P. Romano and R. Schifani, "A life model for epoxy resins subjected to PD activity at different temperatures IEEE Conf. Electr. Insul. Dielectr. Phenomena (CEIDP),Cat. No. 00CH37132, pp. $564-567,2000$.

[40] M. Di Lorenzo del Casale and R. Schifani, "Investigation of temperature effect on an epoxy resin: Aging due to partial discharges", 8th Intern.
Conf. Dielectr. Materials, Measurements and Applications Conf. Publ. No. 473, pp. 509-512, 2000.

[41] M. Di Lorenzo del Casale and R. Schifani, "Direct interaction between partial discharge and temperature on epoxies: Phenomenological life models", J. Phys. D. Appl. Phys., Vol. 35, pp. 33 - 39, 2002.

[42] R. Schifani, R. Candela and P. Romano, "On PD mechanisms at high temperature in voids included in an epoxy resin", IEEE Trans. Dielectr. Electr. Insul., Vol. 8, pp. 589 - 597, 2001.

[43] J.V. Champion, S.J. Dodd, A.S. Vaughan, Y. Zhao and S.J. Sutton, "The effect of voltage, temperature and morphology on electrical treeing in polyethylene blends", $8^{\text {th }}$ Int. Conf. Dielectric Materials, Measurements and Applications, pp. 35 - 40, 2000.

[44] D.W. Auckland, A. Taha and B.R. Varlow, "Correlation of mechanical properties with electrical treeing behaviour at elevated temperatures". 1993 Annual Report., Conference on Electrical Insulation and Dielectric Phenomena, pp. 636-641, 1993.

[45] S.I. Jeon, S.H. Nam, D.S. Shin, I.H. Park, and M.K. Han, "The correlation between partial discharge characteristics and space charge accumulation under AC voltage". IEEE Conf. Electr. Insul. Dielectr. Phenomena (CEIDP), Cat. No. 00CH37132, pp. 653-656, 2000.

[46] P.H.F. Morshuis and J.J. Smit, "Partial Discharges at DC Voltage; Their Mechanism, Detection and Analysis". IEEE Trans. Dielectr. Electr. Insul., Vol. 12, No. 2, pp. 328-340, 2005.

[47] R. Bodega, A. Cavallini, P.H.F. Morshuis, and F.J. Wester, "The effect of voltage frequency on partial discharge activity", IEEE Conf. Electr. Insul. Dielectr. Phenomena (CEIDP),Cat. No. 02CH37372, pp. 685-689, 2002.

[48] R. Bodega, P.H.F. Morshuis, M. Lazzaroni, and F.J. Wester, "PD recurrence in cavities at different energizing methods", IEEE Trans. Instrum. Measur., Vol. 53, pp. 251 - 258, 2004.

[49] D. Fabiani and G.C. Montanari, "The effect of voltage distortion on ageing acceleration of insulation systems under partial discharge activity", IEEE Electr. Insul. Mag., Vol. 17, No. 3, pp. 24 - 33, 2001.

[50] G. Stone, S. Campbell and S. Tetreault, "Inverter-fed drives: which motor stators are at risk?", Industry Applications Magazine, IEEE, Vol. 6, No. 5, pp. 17 - 22, 2000.

[51] M. Kozako, N. Fuse, Y. Ohki, T. Okamoto and T. Tanaka, "Surface degradation of polyamide nanocomposites caused by partial discharges using IEC (b) electrodes", IEEE Trans. Dielectr. Electr. Insul., Vol. 11, pp. 833 - 839, 2004.

[52] M. Kozako, R. Kido, N. Fuse, Y. Ohki, T. Okamoto, and T. Tanaka, "Difference in surface degradation due to partial discharges between polyamide nanocomposite and microcomposite [electrical insulation applications]", IEEE Conf. Electr. Insul. Dielectr. Phenomena (CEIDP), pp. $398-401,2004$.

[53] T. Tanaka, G.C. Montanari, and R. Mulhaupt, "Polymer nanocomposites as dielectrics and electrical insulation-perspectives for processing technologies, material characterization and future applications", IEEE Trans. Dielectr. Electr. Insul., Vol. 11, pp. 763 $784,2004$.

[54] Y.-B. Chen, R.J. Varley and G.P. Simon, "Layered Silicate Nanocomposites Based on Various High Functionality Epoxy Resins: The Influence of Cure Temperature on Morphology, Mechanical Properties and Free Volume", Macromolecules, Vol. 36, pp. 1616 $1625,2003$.

[55] M. Kozako, N. Fuse, K. Shibata, N. Hirai, Y. Ohki, T. Okamoto and T. Tanaka, "Surface change of polyamide nanocomposite caused by partial discharges". IEEE Conf. Electr. Insul. Dielectr. Phenomena (CEIDP), Cat. No. 03CH37471, pp. 75-78, 2003.

[56] P. Zhang, W. Zhang, Y. Liu, Y. Fan and Q. Lei, "Study on coronaresistance of polyimide-nano inorganic composites", IEEE 7th Intern. Conf. Properties and Applications of Dielectric Materials, pp. 1138 1141, 2003. 
[57] N. Fuse, M. Kozako, T. Tanaka, S. Murase and Y. Ohki, "Possible mechanism of superior partial-discharge resistance of polyamide nanocomposites", IEEE Conf. Electr. Insul. Dielectr. Phenomena (CEIDP), IEEE Cat. No. 04CH37584, pp. 322-325, 2004.

[58] M. Kozako, R. Kido, N. Fuse, Y. Ohki, T. Okamoto and T. Tanaka, "Difference in surface degradation due to partial discharges between polyamide nanocomposite and microcomposite [electrical insulation applications]", IEEE Conf. Electr. Insul. Dielectr. Phenomena (CEIDP), IEEE Cat. No. 04CH37584, 2004.

[59] T. Tanaka, "Dielectric-nano-composites with insulating properties", IEEE Trans. Dielectr. Electr. Insul., Vol. 12, No. 5, 2005.

[60] S.A. Al-Ghamdi and B.R. Varlow, "Treeing in Mechanically Prestressed Electrical Insulation", IEEE Trans. Dielectr. Electr. Insul. Vol. 11, pp. 130-135, 2004.

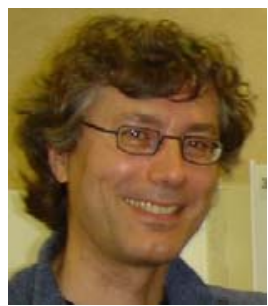

Peter H.F. Morshuis (M'95) was born in The Hague, The Netherlands, on 23 December 1959. In 1986, he received the Master degree in electrical engineering from Delft University of Technology. Between 1986 and 1988, he was involved in studies for NKF Kabel on the effects of defects on the lifetime of high voltage cables and in studies on new cable concepts. Since 1988, he has been a staff member of the High Voltage Group at Delft University of Technology where he was awarded the Ph.D. degree in electrical engineering in 1993 on the topic of ultrawideband electrical and optical studies of partial discharges in solid dielectrics. In 1998, he was a visiting Professor at the University of Bologna. Since 1999, he is an Associate Professor in High Voltage Engineering at Delft University of Technology and he is involved in teaching first year students in the field of electricity and magnetism and M.Sc. students in the field of high voltage dc. His most important fields of interest are HVDC (materials and systems), space charge, partial discharge, and aging of electrical insulation. He is involved in a number of CIGRÉ activities and is an Associate Editor of the IEEE Transactions on Dielectrics and Electrical Insulation. 